\title{
Regional deposition of nebulized hypodense nonisotonic solutions in the human respiratory tract
}

\author{
H-K. Chan*, P.R. Phipps*, I. Gonda*, P. Cook**, R. Fulton**, \\ I. Young ${ }^{\dagger}, \mathrm{G}$. Bautovich**
}

Regional deposition of nebulized hypodense nonisotonic solutions in the human respiratory tract. H-K. Chan, P.R. Phipps, I. Gonda, P. Cook, R. Fulton, I. Young, G. Bautovich. CERS Journals Ltd 1994.

ABSTRACT: Deposition of nonisotonic therapeutic and diagnosis aerosols can cause changes in airway fluid composition and bronchoconstriction in sensitive subjects. "Hypodense" aerosols containing a relatively low concentration of droplets in the carrier air were used in the studies of regional deposition of radiolabelled nebulized solutions of hypo- and hypertonic saline, in order to investigate whether the number of droplets per volume of carrier can affect deposition.

Solutions with and without $0.5 \%$ nedocromil sodium were nebulized in order to examine the effects of a potential modifier of the rates of heat and mass transfer. The deposition was quantified using penetration index (PI) calculated from images obtained by single photon emission computerized tomography (SPECT) in 11 healthy volunteers per study.

There was an increase in the penetration index $(10.9 \%$, for the saline only; $15.5 \%$, for the nedocromil study) of the hypotonic compared to the hypertonic aerosol, although the initial size distribution of both types of aerosols was very similar (mass median aerodynamic diameter (MMAD) 3.7 and $3.8 \mu \mathrm{m}$; geometric standard deviation (GSD) 1.8 and 1.5 for the hypo- and hypertonic aerosols, respectively).

The present results confirm the effects of tonicity on deposition of aerosols found in a parallel study reported in this issue of the Journal. They also give support to the theory that, in addition to the concentration of the nebulized solutions, the number of droplets per volume of the carrier air is a factor affecting deposition of aqueous aerosols. The presence of $0.5 \%$ nedocromil sodium in the solutions did not appear to interfere with the processes of heat and water transfer in the airways. Eur Respir J., 1994, 7, 1483-1489.
*Dept of Pharmacy, University of Sydney, Sydney, NSW, Australia. Depts of **Nuclear Medicine and Thoracic Medicine, Royal Prince Alfred Hospital, NSW, Australia.

Correspondence: H-K. Chan Genentech Inc.

460 Point San Bruno Blvd

South San Francisco

CA 94080

USA

Keywords: Aerosols

asthma

lung deposition

nedocromil sodium

nonisotonic inhalation solutions radioaerosols

Received: November 81993

Accepted after revision April 171994

This work was supported by a contract from Fisons Plc (UK) who also supplied nedocromil sodium.
Aerosols prepared by nebulization of nonisotonic saline solutions have been used for bronchial hyperreactivity testing [1-4]. The greatest perturbation of the airway fluid composition is most likely to be in the large airways, in view of the fact that the total amount of the periciliary fluid in the first 12 airway generations is less than $1 \mathrm{ml}$ [4]. Many pharmaceutical aerosol formulations are nonisotonic [5], or they contain hygroscopic ingredients $[6,7]$. A large number of theoretical investigations [7-16] and in vitro experimental studies [6-8, 17] have been carried out to determine hygroscopic growth or shrinkage of aerosolized particles. In vivo measurements have also been made by comparing the size distribution of the inhaled and exhaled aerosols [18-21].

Single photon emission computerized tomography (SPECT) [22] was used to investigate the distribution of aerosols "in vivo" of nonisotonic saline solutions prepared by conventional nebulizers [23-26]. The differences observed between the deposition of hypo- and hypertonic nebulized solutions in normal subjects were somewhat less than expected on theoretical grounds [23]. One possible explanation for this discrepancy was that, during the inhalation, the aerosols significantly change the composition of the airway fluid such that the driving force for the hypertonic aerosol to grow, or for the hypotonic aerosol to shrink, is reduced. In order to test this hypothesis, we prepared "hypodense" aerosols, which contain a very low number of aerosol droplets per unit volume of carrier air. As a result, any possible physicochemical change in the airway environment (e.g. tonicity of the periciliary fluid) should be minimized. In this sense, the hypodense aerosols resemble the aerosols generated by dry powder inhalers or by the propellantdriven metered dose inhalers, which also contain minute quantities of materials (typically $<5 \mathrm{mg}$ ). Hypodense nonisotonic aerosols are also less likely to cause bronchoconstriction in sensitive subjects, because neither the dose, nor the rate of delivery, should be high enough to provoke bronchospasm.

Our investigations consisted of two parts: 1) a study with 0.3 and $5 \%(\mathrm{w} / \mathrm{v})$ saline solutions; and 2) a study in which the same saline solutions also contained $0.5 \%$ nedocromil sodium. Nedocromil sodium has been found to be more potent than cromolyn (sodium cromoglycate), 
not only in inhibition of histamine release from human lung mast cell in vitro [27], but also for in vivo prophylaxis of asthma induced by adenosine 5'-monophosphate (AMP) [28], cold air [29], sodium metabisulphite [30], or exercise [31]. It was proposed that the pharmacological actions of cromolyn could be related to its effects on the heat and water transfer in the airways [32, 33]. Nedocromil sodium may have similar properties. If nedocromil sodium interfered directly with these physical processes, then aerosols containing this substance would be expected to grow or shrink to a different extent, or at different rates, than pure saline aerosols, and this should affect the deposition pattern in the respiratory tract.

\section{Materials and methods}

The study protocols were approved by the Ethics Review Committee at the Royal Prince Alfred Hospital. Written consent was obtained from each subject before participation. Normal healthy, nonasthmatic volunteers were recruited. The subjects inhaled on two separate occasions under controlled breathing conditions either 5 or $0.3 \%$ radiolabelled aqueous saline aerosols (in one study without, and in the second study with, $0.5 \%$ nedocromil sodium). The regional deposition of the radioaerosol was followed by external scintigraphy [22, 23].

Prior to any radioaerosol inhalation, lung functions and volumes were measured before and after challenging the subject with nonisotonic saline aerosols to confirm normal lung function (taken as $>80 \%$ predicted value for forced expiratory volume in one second $\left(\mathrm{FEV}_{1}\right)$, functional vital capacity (FVC), peak flow rate (PEF), and midexpiratory peak flow rate (MEPF) [34]) and lack of bronchial hyperreactivity (fall in $\mathrm{FEV}_{1}$ postchallenge $\leq 10 \%$ ). In addition, haematological and biochemical investigations were performed to verify the absence of clinical abnormality before and after their participation in the study. Seventeen subjects were enrolled into the study with saline alone. Three subjects had to be rejected because of technical problems with scintigraphy during the study. Three further subjects could not control their breathing within the prescribed limits. The remaining 11 subjects were 5 females (aged 18-35 yrs, height $155-176 \mathrm{~cm}$ ) and 6 males (aged 19-33 yrs, height 167-185 $\mathrm{cm})$. In the nedocromil sodium study, 13 subjects were enrolled; one subject was unable to control breathing within the prescribed limits; a second subject admitted after the study that he did not report a feeling of tightness in the chest before the first inhalation, thus, the results from this subject were not included in the analyses. Therefore, 6 females (aged 19-41 yrs, height 156-173 $\mathrm{cm}$ ) and 5 males (aged 22-33 yrs, height 171-178 cm) remained in this study.

The aerosols were generated from a nebulizer system, which consisted of an Inspiron jet nebulizer (Mini-Neb, Inspiron, a division of Intertech Resources Inc., Rancho Cucamonga, CA, USA); the air was supplied by an electrical pump (Aeromist, Medical Industries Australia) at 2.9 and $4.5 l \cdot \mathrm{min}^{-1}$, respectively. As in our previous studies [22, 23], precautions were taken, by using humidified dilution air $[24,26,35]$, to prevent droplet evapora- tion before entry of the aerosol to the mouth. This was confirmed by collection of aerosol and assuring that the osmolarity of the collected solution was the same as that of the solution in the nebulizer. A baffle, which did not limit the flow, was placed in the inhalation line in order to reduce the concentration of the droplets in the aerosol. Using several designs and several flow rates, the operating conditions were found such that the aerosol size distributions for the hypo- and hypertonic solutions were similar (mass median aerodynamic diameter (MMAD) $3.7 \pm 0.2$ and $3.8 \pm 0.3 \mu \mathrm{m}$; geometric standard deviation (GSD) $1.8 \pm 0.1$ and $1.5 \pm 0.1 ; \mathrm{n}=21$ and 17 , respectively). These measurements on a cascade impactor [35] also confirmed that the aerosol particle size distribution of the hypodense aerosols was similar to the conventional "dense" aerosols used in our previous studies (MMAD 3.7-3.8 $\mu \mathrm{m}$; GSD 1.4-1.5) [23]. However, the droplet output from the system was only approximately 0.05 and $0.01 \mathrm{ml} \cdot \mathrm{min}^{-1}$ for the hypotonic and hypertonic saline aerosols, respectively, (compared to $0.23 \mathrm{ml} \cdot \mathrm{min}^{-1}$ with the dense aerosols used in our previous studies [23]). Therefore, by calculation based on mass balance, the maximal change in the tonicity of periciliary fluid for the first 16 airway generations would not exceed $15 \%$, assuming no replenishment of the airway fluid [4].

Each subject inhaled the hypertonic and hypotonic aerosols (with or without nedocromil sodium) on two separate occasions at least $20 \mathrm{~h}$ apart, but within 7 days. The order of hypertonic/hypotonic was randomized and the studies were single-blind. The volunteers inhaled the aerosols for 3-5 min, using their own tidal breathing in a controlled and reproducible manner by application of a computerized breathing circuit $[22,23,36]$. The aerosols were labelled with ${ }^{99 m}$ technetium-diethylenetriaminepentaacetic acid (99mTc-DTPA) [22]. Immediately after the aerosol inhalation, the subjects gargled and rinsed their mouth with water, then drank water ad libitum and swallowed a slice of bread to minimize residual radioactivity in the oesophagus. With the subject lying supine, transmission and emission SPECT imaging of the chest was then carried out $[22,23]$. In order to examine the effect of regional clearance of the deposited aerosol during the SPECT acquisition, anterior and posterior planar images of the respiratory tract were also taken immediately before and after the SPECT acquisition [23, 37].

The SPECT penetration index (PI) was obtained from mid-lung coronal slices; both the SPECT PI and the PI derived from the geometric mean of the anterior and posterior images were defined as the ratio of the amount of radioactivity in the peripheral lung to that in the central region, including the trachea; only the right hand side of the thorax was used [22, 23]. The difference in the aerosol deposition patterns was measured in terms of the d-value which was defined as:

$$
\mathrm{d} \%=100 \times \frac{[\text { PI (hypotonic) }- \text { PI (hypertonic) }]}{\text { PI (hypotonic) }}
$$

The statistical significance of the d-values was assessed using one-tailed t-test and one-tailed Wilcoxon test [38]. 
Table 1. - Mean breathing parameters for each subject in the saline study

\begin{tabular}{|c|c|c|c|c|c|c|c|c|c|c|}
\hline \multirow[b]{2}{*}{$\begin{array}{l}\text { Subject } \\
\text { No. }\end{array}$} & \multicolumn{5}{|c|}{ Hypotonic aerosol } & \multicolumn{5}{|c|}{ Hypertonic aerosol } \\
\hline & $\begin{array}{l}\mathrm{V}_{\mathrm{T}} \\
\mathrm{ml}\end{array}$ & $\begin{array}{c}\mathrm{PIF} \\
l \cdot \mathrm{min}^{-1}\end{array}$ & $\begin{array}{c}\mathrm{PEF} \\
l \cdot \mathrm{min}^{-1}\end{array}$ & $\begin{array}{c}\text { Ttot } \\
\mathrm{s}\end{array}$ & $\begin{array}{r}\text { PI } \\
\mathrm{s}\end{array}$ & $\begin{array}{l}\mathrm{VT} \\
\mathrm{ml}\end{array}$ & $\begin{array}{l}\mathrm{PIF} \\
l \cdot \mathrm{min}^{-1}\end{array}$ & $\begin{array}{c}\mathrm{PEF} \\
l \cdot \mathrm{min}^{-1}\end{array}$ & $\begin{array}{c}\text { Ttot } \\
\mathrm{s}\end{array}$ & $\begin{array}{c}\text { PI } \\
\mathrm{s}\end{array}$ \\
\hline 1 & 627 & 34.7 & 34.9 & 3.9 & 0.06 & 656 & 32.3 & 36.5 & 3.9 & 0.04 \\
\hline 2 & 583 & 31.8 & 29.2 & 3.8 & 0.05 & 549 & 28.2 & 30.6 & 3.9 & 0.07 \\
\hline 3 & 658 & 27.5 & 24.6 & 5.2 & 0.05 & 642 & 31.2 & 21.5 & 5.2 & 0.08 \\
\hline 4 & 1080 & 39.3 & 35.7 & 6.4 & 0.07 & 1095 & 37.7 & 41.2 & 6.8 & 0.29 \\
\hline 5 & 1098 & 39.1 & 38.7 & 6.4 & 0.01 & 1095 & 39.9 & 33.1 & 6.4 & 0.03 \\
\hline 6 & 619 & 29.4 & 33.9 & 4.3 & 0.06 & 608 & 28.8 & 35.4 & 4.3 & 0.06 \\
\hline 7 & 579 & 25.7 & 22.5 & 5.7 & 0.15 & 566 & 29.0 & 20.8 & 5.6 & 0.21 \\
\hline 8 & 896 & 34.1 & 23.0 & 8.7 & 0.61 & 894 & 27.7 & 22.6 & 8.7 & 0.46 \\
\hline 9 & 489 & 30.0 & 24.1 & 3.7 & 0.14 & 483 & 32.3 & 22.8 & 3.7 & 0.15 \\
\hline 10 & 756 & 32.0 & 25.1 & 5.4 & 0.21 & 719 & 32.1 & 25.7 & 5.2 & 0.36 \\
\hline 11 & 557 & 23.8 & 24.3 & 5.0 & 0.35 & 559 & 28.3 & 23.3 & 5.0 & 0.41 \\
\hline
\end{tabular}

VT: tidal volume; PIF: peak inspiratory flow rate; PEF: peak expiratory flow rate; Ttot: total time of a breath cycle; PI: inspiratory pause.

Table 2. - Mean breathing parameters for each subject in the nedocromil study

\begin{tabular}{|c|c|c|c|c|c|c|c|c|c|c|}
\hline \multirow[b]{2}{*}{$\begin{array}{l}\text { Subject } \\
\text { No. }\end{array}$} & \multicolumn{5}{|c|}{ Hypotonic aerosol } & \multicolumn{5}{|c|}{ Hypertonic aerosol } \\
\hline & $\begin{array}{l}\mathrm{V}_{\mathrm{T}} \\
\mathrm{ml}\end{array}$ & $\begin{array}{c}\mathrm{PIF} \\
l \cdot \mathrm{min}^{-1}\end{array}$ & $\begin{array}{c}\mathrm{PEF} \\
l \cdot \mathrm{min}^{-1}\end{array}$ & $\begin{array}{c}\text { Ttot } \\
\mathrm{s}\end{array}$ & $\begin{array}{r}\text { PI } \\
\mathrm{s}\end{array}$ & $\begin{array}{l}\text { VT } \\
\mathrm{ml}\end{array}$ & $\begin{array}{l}\text { PIF } \\
l \cdot \mathrm{min}^{-1}\end{array}$ & $\begin{array}{c}\mathrm{PEF} \\
l \cdot \mathrm{min}^{-1}\end{array}$ & $\begin{array}{c}\text { Ttot } \\
\mathrm{s}\end{array}$ & $\begin{array}{r}\mathrm{PI} \\
\mathrm{s}\end{array}$ \\
\hline 1 & 786 & 21.7 & 17.9 & 8.1 & 0.43 & 775 & 23.7 & 18.3 & 8.1 & 0.57 \\
\hline 2 & 635 & 20.7 & 21.7 & 5.4 & 0.13 & 633 & 25.0 & 24.5 & 5.4 & 0.25 \\
\hline 3 & 723 & 18.8 & 15.4 & 9.7 & 0.42 & 770 & 22.3 & 16.2 & 9.7 & 0.32 \\
\hline 4 & 1259 & 34.7 & 34.2 & 10.0 & 0.44 & 1175 & 28.7 & 19.9 & 10.1 & 0.42 \\
\hline 5 & 450 & 20.9 & 19.8 & 4.8 & 0.17 & 433 & 21.8 & 18.9 & 4.6 & 0.34 \\
\hline 6 & 499 & 28.6 & 23.0 & 4.9 & 0.60 & 521 & 27.1 & 22.7 & 4.9 & 0.53 \\
\hline 7 & 636 & 28.5 & 22.1 & 5.0 & 0.16 & 637 & 29.0 & 23.4 & 4.4 & 0.04 \\
\hline 8 & 797 & 33.7 & 29.5 & 4.9 & 0.13 & 805 & 32.3 & 29.4 & 4.9 & 0.07 \\
\hline 9 & 645 & 33.4 & 33.1 & 3.6 & 0.10 & 651 & 34.7 & 33.5 & 3.6 & 0.16 \\
\hline 10 & 510 & 27.9 & 19.3 & 4.7 & 0.43 & 511 & 30.4 & 20.6 & 4.7 & 0.57 \\
\hline 11 & 1027 & 42.9 & 34.6 & 5.2 & 0.14 & 1067 & 45.1 & 36.4 & 5.0 & 0.20 \\
\hline
\end{tabular}

For abbreviations see legend to table 1.

\section{Results}

The breathing characteristics of the subjects are presented in tables 1 and 2. The breath-by-breath analysis of the breathing parameters on any particular study day showed that the coefficient of variation of the mean values for any one individual was less than $25 \%$, except for subject No. 4 in the saline study, whose expiratory flow rate varied by $27.7 \%$. Considering the intra-individual variation from one study day to another, the group mean $\mathrm{d}$-values were not statistically different from zero, except for the inspiratory pause in the saline study and the total time of the breath cycle (Ttot) in the nedocromil sodium study. However: 1) the absolute differences in the mean inspiratory pause $(\mathrm{PI})$, were within $0.2 \mathrm{~s}$; and 2 ) the mean $\%$ d-value for Ttot was only $2.5 \%$. The intra-individual d-values were again less than $25 \%$ for all subjects and all parameters, except for the following: subject No. 4 in the nedocromil sodium study had a $42 \%$ difference in the expiratory flow between the two study days; when this subject was omitted from the analysis of the deposition data, the group results remained virtually unchanged.
Thus, we do not think that any of these variations could have introduced a significant bias to the deposition results.

\section{Saline study}

The SPECT PI values for the 11 subjects are plotted as hypertonic versus hypotonic results in figure 1 . There is a clear tendency for higher deposition in the lung periphery for the hypotonic as compared to the hypertonic aerosol. A similar trend was obtained when the radioactivity in the central regions was expressed as a percentage of the whole lung. Here (fig. 2) the data indicate more central deposition for the hypertonic than the hypotonic aerosol. Figure 3 shows the d-values for the hypodense aerosols together with the previous results [22] for the isotonic aerosols $(2.6$ and $5.5 \mu \mathrm{m})$ with the central region including the trachea [23]. Also shown are nonisotonic dense (conventional number of droplets per volume of carrier air) saline aerosols (concentration of solutions 0.3 and $4.5 \%$; droplet sizes $3.7-3.8 \mu \mathrm{m}$ ) [23]. 


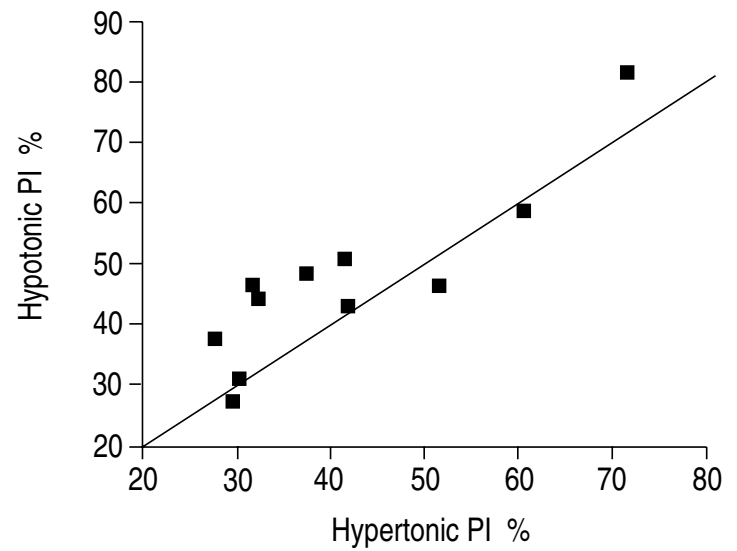

Fig. 1. - Graph showing that the single photon emission computerized tomography (SPECT) penetration index (PI) for the hypotonic aerosols is consistently higher than the PI for hypertonic saline aerosols in normal subjects. The solid line shows the hypothetical situation in which the PI's for hyper- and hypotonic aerosols would be identical.

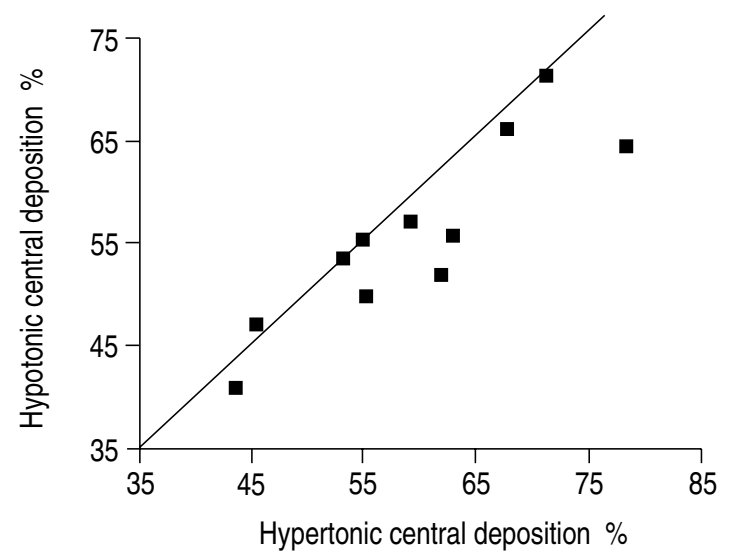

Fig. 2. - Graph showing that the deposition in the central region (including trachea) of the lung for the hypotonic aerosol is consistently lower than that for the hypertonic saline aerosols in normal subjects. The solid line shows the hypothetical situation in which the central deposition for the two types of aerosols would be identified.

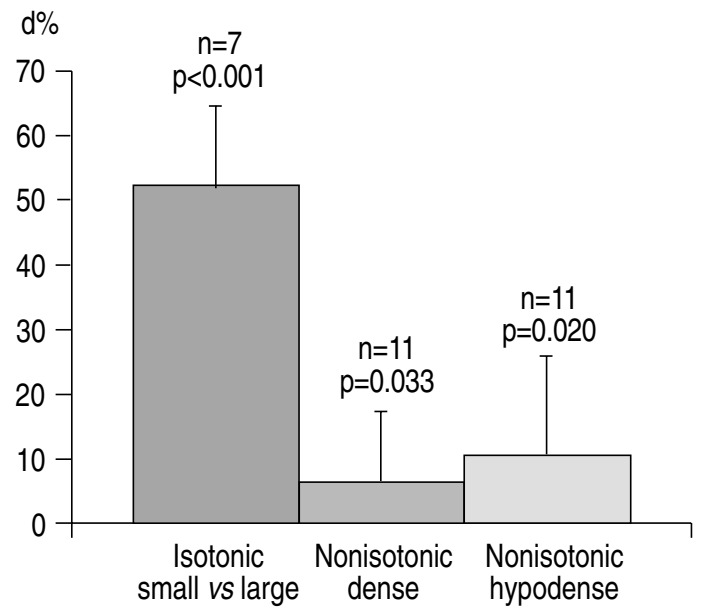

Fig. 3. - Difference in the penetration index (PI) (or deposition pattern) for the various types of aerosol as expressed by the d-value. "Isotonic small vs large" is from [22] with the central region modified to include the trachea [23]. "Nonisotonic dense" aerosols had the same tonicities and size distributions as in the current study, but 5-20 times greater number of droplets per volume of carrier air [23]. "Nonisotonic hypodense" are the results from the current study.
The mean d-value for the isotonic aerosols (2.6 and 5.5 $\mu \mathrm{m})$ was $52.4 \%$ [23]. The previous mean d-value for the nonisotonic dense aerosol was only about $6 \%$ [23]. The present data showed a mean d-value of 1.6 times that of the nonisotonic "dense" aerosols; also, the statistical tests showed more significant $p$-values for the difference in PI when using hypodense aerosols (t-test $\mathrm{p}=0.020$; Wilcoxon test $\mathrm{p}=0.034$ ). The results, thus, support the hypothesis $[15,39]$ that the number density of nonisotonic aerosols plays a role in their deposition.

A potential problem with SPECT was that regional clearance of the deposited aerosols could occur during the image acquisition, leading to artefacts in the calculation of PI. To examine this, the pre- and post-SPECT planar images were collected, and the PI values were obtained. The d-values were calculated for these planar images as:

$$
\mathrm{d} \%=100 \times \frac{(\text { post-SPECT PI })-(\text { pre-SPECT PI })}{\text { post-SPECT PI }}
$$

The results showed a mean d-value of $-5.88 \%$ (t-test $\mathrm{p}=0.020$; Wilcoxon test $\mathrm{p}=0.046$ ) and $-3.88 \%$ (t-test $\mathrm{p}=0.16$; Wilcoxon test $\mathrm{p}=0.13$ ) for the hypertonic and hypotonic aerosols, respectively, indicating that there was in fact some relative redistribution of the aerosols in the lung, which reached statistical significance for the hypertonic aerosols. However, the difference between the dvalues for the hypo- and hypertonic aerosols was not statistically significant ( $\mathrm{t}$-test $\mathrm{p}=0.060$; Wilcoxon test $\mathrm{p}=0.063$ ). Therefore, it could not account for the difference in the aerosol deposition obtained from SPECT. More importantly, it was SPECT, but not the planar images, which was capable of showing a significant difference between the PI for the hypo- and hypertonic aerosols (mean d-value for PI: pre-SPECT planar images $=-2.3 \%$; t-test $\mathrm{p}=0.26$; Wilcoxon test $\mathrm{p}=0.25$; SPECT study: mean $\mathrm{d}$-value $=10.9 \%$; t-test $\mathrm{p}=0.020$; Wilcoxon test $\mathrm{p}=0.034$ ).

\section{Nedocromil sodium study}

The SPECT PI data and the central lung region data for 11 subjects are plotted in figures 4 and 5 . The overall results were similar to the study without the drug: the peripheral lung deposition for the hypotonic aerosol was higher than for the hypertonic solution. The mean $\mathrm{d}$ value for PI was $15.5 \%$ (t-test $\mathrm{p}=0.0019$; Wilcoxon test $\mathrm{p}=0.006$ ); i.e. it was similar in magnitude to the salineonly study, but statistically even more significant.

On examination of the PI data of the pre- and postSPECT planar images, we found the mean value of $d$ to be $-3.27 \%$ (t-test $\mathrm{p}=0.18$; Wilcoxon test $\mathrm{p}=0.225$ ) and $6.77 \%$ (t-test $\mathrm{p}=0.021$; Wilcoxon test $\mathrm{p}=0.015$ ) for the hypertonic and hypotonic aerosols, respectively. The results thus showed that, in contrast to the saline only study, the relative clearance of the aerosol towards the central lung region occurred more for the hypotonic than the hypertonic solutions, as observed with "dense" nonisotonic aerosols [23]. Although the difference between these two d-values was not statistically significant (t-test $\mathrm{p}=0.44$; Wilcoxon test $\mathrm{p}=0.13$ ), the data indicate 


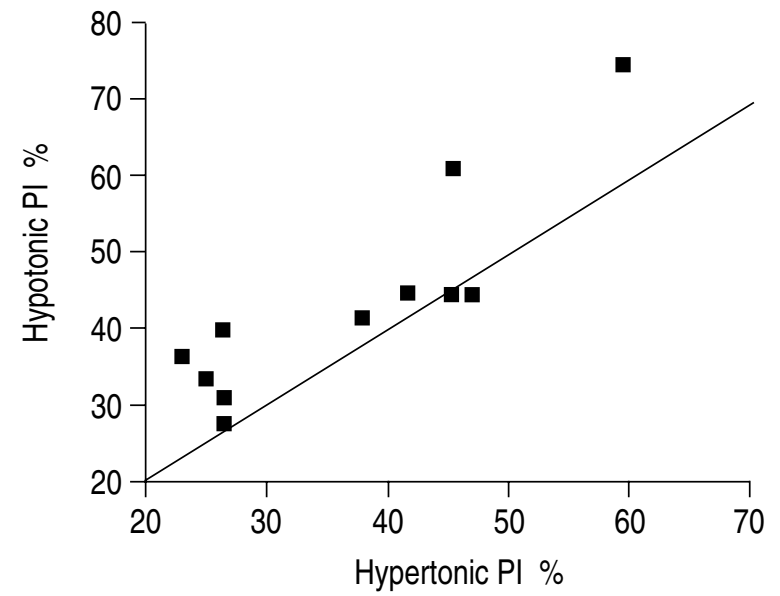

Fig. 4. - Graph showing that the SPECT penetration index (PI) in normal subjects for the hypotonic saline aerosols containing $0.5 \%(\mathrm{w} / \mathrm{v})$ nedocromil sodium is consistently higher than the PI for hypertonic saline aerosols containing the same concentration of the drug. The solid line shows the hypothetical situation in which the PI's for the two types of aerosols would be identical.

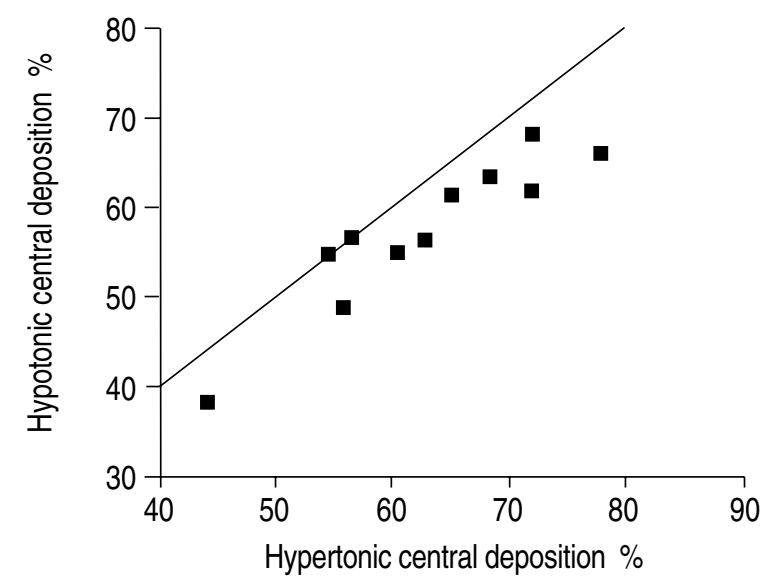

Fig. 5. - Graph showing that the deposition in normal subjects in the central region (including trachea) of the lung for the hypotonic aerosol containing $0.5 \%(\mathrm{w} / \mathrm{v})$ nedocromil sodium is consistently lower than that for the hypertonic saline aerosols containing the same concentration of nedocromil sodium. The solid line shows the hypothetical situation in which the central deposition for the two types of aerosols would be identical.

that if there had been no redistribution of the deposited radioactivity during the SPECT acquisition, the difference in the PI for the nonisotonic aerosols would have been found to be even bigger.

As in the saline only study, the PI derived from SPECT, but not that calculated from the planar images, was capable of demonstrating a significant difference in PI between the hypo- and hypertonic aerosol (mean d-value for PI: pre-SPECT planar image $=5.8 \%$; t-test $\mathrm{p}=0.10$; Wilcoxon test $\mathrm{p}=0.175$; mean d-value in SPECT study $=15.5 \%$; t-test $\mathrm{p}=0.0019$; Wilcoxon test $\mathrm{p}=0.006$ ).

\section{Discussion}

Firstly, the results verified that SPECT shows a better ability to identify differences in deposition than the more conventional planar techniques [22]. Secondly, they confirmed the previous findings with the "dense" aerosols (i.e. aerosols having a high number concentration of droplets) that there was a difference in the deposition of the nonisotonic saline solutions, with a higher PI value for the hypotonic aerosol compared to the hypertonic aerosol [23-26]. The present results, however, showed a somewhat larger difference in the PI between the two aerosols, suggesting that the number density of the aerosol plays a role in the regional deposition in the lung. This greater difference, compared to the "dense" aerosols, is consistent with the expectation that hypodense aerosols will cause minimal perturbations of the airway fluid. This would imply that there is very little, if any, effect of the droplet deposition on humidity of the airways, airway calibre or mucociliary clearance when using hypodense aerosols. Thirdly, it should be noticed that the present d-values are still much lower than those obtained for the isotonic aerosols, with initial sizes 2.6 and $5.5 \mu \mathrm{m}[22,23]$. If the hypo- and hypertonic aerosols equilibrated with the water vapour pressure corresponding to that in the alveoli (i.e. if the droplets became isotonic), their size should change from 3.7 to 2.6 and $6.6 \mu \mathrm{m}$, respectively. The experimental results with both the dense and the hypodense nonisotonic aerosols show that the difference in PI for the aerosols of different tonicity is much less than that expected for the difference in deposition of 2.6 and $6.6 \mu \mathrm{m}$ aerosol droplets (c.f. the results with the small and large isotonic aerosol study [22]). The fact that the hypodense aerosols show a bigger difference than the dense aerosols indicates that the latter appear to change the composition of the airway fluid to the extent that they attenuate their own change in droplet size. Ideally, this hypothesis should be tested in a randomized cross-over study in which the same subjects inhale both normal and hypodense aerosols.

The current results with the hypodense aerosols support the conclusions from the previous findings [23] that the droplets do not seem to change their size instantaneously to the equilibrium values. It has been predicted by theoretical modelling [8-16] that droplet equilibration takes an appreciable length of time. Furthermore, there is a gradient of relative humidity in the airways $[8,40$, 41]. Indeed, it is known that the fluid lining the upper airways is hypertonic [42], so that the hypertonic aerosols would not grow in this part of the respiratory tract to the isotonic value (however, the same fact should enhance the evaporation of the hypotonic aerosols).

Until recently, theoretical models of hygroscopic aerosol deposition have considered only the behaviour of a single particle in an environment of unlimited capacity for exchange of water vapour $[15,39]$. This is not realistic for dense aerosols, such as those prepared by conventional jet nebulizers. Such theoretical models are more appropriate for low number density ("hypodense") aerosols, such as those used in this study, or generated by the low dose dry powder inhalers and propellant-driven metereddose inhalers.

The presence of the drug nedocromil sodium did not appear to make any significant change to the difference in deposition patterns of hyper- and hypotonic aerosols. It should be noted that $0.5 \%$ nedocromil sodium in the 
saline solutions made a negligible impact on the osmolarity. The dose was too small to observe any physiological changes. These results indicate that the presence of $0.5 \%$ nedocromil sodium in saline did not affect the dynamics of droplet growth, or shrinkage.

The use of hypodense aerosols in deposition studies seems to overcome the problem of perturbation of the composition of the airway fluid by the aerosol. This would be particularly important in hyperreactive subjects, where such changes could lead to a deposition pattern dominated by the effect of aerosol-induced bronchospasm $[23,25,26]$.

Acknowledgements: The authors thank Fisons plc, Pharmaceutical Division, UK for their financial support, and S. Anderson and D. Bailey for helpful suggestions.

\section{References}

1. Schoeffel RE, Anderson SD, Altounyan REC. Bronchial hyperreactivity in response to inhalation of ultrasonically nebulised solutions of distilled water and saline. Br Med J 1981; 283: 1285-1287.

2. Anderson SD, Schoeffel RE, Finney M. Evaluation of ultrasonically nebulised solutions for provocation testing in patients with asthma. Thorax 1983; 38: 284-291.

3. Anderson SD, Smith CM. Osmotic challenges in assessment of bronchial hyperresponsiveness. Am Rev Respir Dis 1991; 143: S43-S46.

4. Anderson SD, Daviskas E, Smith CM. Exercise-induced asthma: a difference in opinion regarding the stimulus. Allergy Proc 1989; 10: 215-226.

5. Fois RA, Gonda I, Chan H-K. Tonicity of some commonly used drug preparations for nebulisation. Aust J Hosp Pharm 1986; 16: 19-21.

6. Gonda I, Kayes JB, Groom CV, Fildes FJT. Characterisation of hygroscopic inhalation aerosols. In: StanleyWood NG, Allen T, eds. Particle Size Analysis. 1981; Chichester, Wiley Heyden Ltd, 1982; pp. 31-43.

7. Smith G, Hiller C, Mazumder M, Bone R. Aerodynamic size distribution of cromolyn sodium at ambient and airway humidity. Am Rev Respir Dis 1980; 121: 513-517.

8. Morrow PE. Factors determining hygroscopic aerosol deposition in airways. Physiol Rev 1986; 66: 330-376.

9. Muller WJ, Hess GD, Scherer PW. A model of cigarette smoke particle deposition. Am Ind Hyg Assoc J 1990; 51: 245-256.

10. Ferron GA. The size of soluble aerosol particles as a function of the humidity of the air. Application to the human respiratory tract. J Aerosol Sci 1977; 8: 251-267.

11. Ferron GA, Haider B, Kreyling WG. Aerosol particle growth in the human airways using a calculated humidity profile. J Aerosol Sci 1983; 14: 196-199.

12. Martonen TB, Bell KA, Phalen RF, Wilson AF, Ho A. Growth rate measurements and deposition modelling of hygroscopic aerosols in human tracheobronchial models. Ann Occup Hyg Assoc J 1982; 26: 93-107.

13. Persons DD, Hess GD, Muller WJ, Scherer PW. Airway deposition of hygroscopic heterodispersed aerosols: results of a computer calculation. J Appl Physiol 1987; 63: $1195-1204$.

14. Persons DD, Hess GD, Scherer PW. Maximization of pulmonary hygroscopic aerosol deposition. J Appl Physiol 1987; 63: 1205-1209.
15. Eisner AD, Graham RC, Martonen TB. Coupled mass and energy transport phenomena in aerosol/vapor-laden gases. I. Theory of the hygroscopic aerosol effects on temperature and relative humidity patterns of inspired air. J Aerosol Sci 1990; 21: 833-848.

16. Cocks AT, Fernando R. The growth of sulphate aerosols in the human airways. J Aerosol Sci 1982; 13: 919.

17. Bell K, Ho AT. Growth rate measurements of hygroscopic aerosols under conditions simulating the respiratory tract. J Aerosol Sci 1981; 12: 247-254.

18. Dautrebande L, Walkenhorst T. Über die Retention von Kochsalzteilchen in den Atemwegen. In: Davies CN, ed. Inhaled Particles and Vapours. Oxford, Pergamon Press, 1960; pp. 110-120.

19. Hicks JF, Pritchard JN, Black A, Megaw WJ. Experimental evaluation of aerosol growth in the human respiratory tract. In: Aerosols: Formation and Reactivity. Proceedings of the Second International Aerosol Conference. Oxford, Pergamon Press, 1986; pp. 244-247.

20. Anselm A, Gebhart J, Heyder J, Ferron G. Human inhalation studies of hygroscopic particles in the respiratory tract. In: Aerosols, Formation and Reactivity. New York, Pergamon Press, 1986; pp. 252-255.

21. Anselm A, Heibel J, Gebhart J, Ferron G. "In vivo" studies of growth factors of sodium chloride particles in the human respiratory tract. J Aerosol Sci 1990; 21 (Suppl. 1): S427-S430.

22. Phipps PR, Gonda I, Bailey DL, Borham P, Bautovich $\mathrm{G}$, Anderson SD. Comparisons of planar and tomographic gamma scintigraphy to measure the penetration index of inhaled aerosols. Am Rev Respir Dis 1989; 139: 1516-1523.

23. Phipps PR, Gonda I, Anderson SD, Bailey D, Bautovich G. Regional deposition of saline aerosols of different tonicities in normal and asthmatic subjects. Eur Respir $J$ 1994; 7: 1474-1482

24. Phipps PR, Gonda I. Some consequences of instability of aqueous aerosols produced by jet and ultrasonic nebulizers. Proc. 3rd International Aerosol Conference, September 24-27, 1990, Kyoto, Japan. In: Masuda S, Takahashi K, eds. Aerosols: Science, Industry, Health and Environment. Oxford, Pergamon Press, 1990; Vol. 1: pp. 227-230.

25. Phipps PR, Gonda I, Bailey DL, Anderson SD, Bautovich G. Penetration index $(\mathrm{PI})$ of hypertonic $(\mathrm{H})$ and isotonic (I) aerosols in asthmatics. 8th Congress of the International Society for Aerosols in Medicine, Davos, Switzerland, April 1991. J Aerosol Med 1991; 4 (Suppl. 1: P74): 24.

26. Phipps PR. Characterization and Pulmonary Deposition of Therapeutic and Diagnostic Aqueous Aerosols. $\mathrm{PhD}$ Thesis, University of Sydney, Sydney, Australia, 1990.

27. Leung KBP, Flint KC, Brostoff J, et al. Effect of sodium cromoglycate and nedocromil sodium on histamine secretion from human lung mast cells. Thorax 1988; 43: 756-761.

28. Richards R, Phillips GD, Holgate ST. Nedocromil sodium is more potent than sodium cromoglycate against AMPinduced bronchoconstriction in atopic asthmatic subjects. Clin Exp Allergy 1989; 19: 285-291.

29. Del Bono L, Dente FL, Patalano F, Del Bono N. Protective effect of nedocromil sodium and sodium cromoglycate on bronchospasm induced by cold air. Eur J Respir Dis 1986; 69: 268-270.

30. Dixon CMS, Ind PW. Inhaled sodium metabisulphite induced bronchoconstriction: inhalation by nedocromil 
sodium and sodium cromoglycate. Br J Clin Pharmacol 1990; 30: 371-376.

31. Konig P, Hordvik NL, Kreutz C. The preventive effect and duration of action of nedocromil sodium and cromolyn sodium on exercise-induced asthma (EIA) in adults. $J$ Allergy Clin Immunol 1987; 79: 64-68.

32. Pichurko BM, McFadden ER Jr, Bowman F, Solway J, Burns S, Dowling N. Influence of cromolyn sodium on airway temperature in normal subjects. Am Rev Respir Dis 1984; 130: 1002-1005.

33. Romanin Chr, Reinsprecht M, Pecht I, Schindler H. The antiallergic drug cromolyn is a potent blocker of $\mathrm{Cl}^{-}$ channel activity in rat mucosal mast cells. Naunyn Sch Arch Pharmacol 1991; 343 (Suppl.): R79.

34. Goldman AI, Becklake MP. Respiratory function tests: normal values at medium altitudes and the prediction of normal results. Am Rev Respir Dis 1959; 79: 457-467.

35. Phipps P, Borham P, Gonda I, Bailey D, Bautovich G, Anderson S. A rapid method for the evaluation of radioaerosol delivery systems. Eur J Nucl Med 1987; 13: $183-186$.
36. Phipps PR, Gonda I, Anderson SD. Apparatus for the control of breathing pattern during aerosol inhalation. $J$ Aerosol Med 1992; 5: 155-170.

37. Chan HK. Use of single photon emission computed tomography in aerosol studies. J Aerosol Med 1993; 6: 23-36.

38. Minitab Reference Manual, Release 7, Minitab Inc., State College, PA, USA, 1989; Chps. 6 and 10.

39. Gonda I. Therapeutic and diagnosis aerosols for delivery of agents to the respiratory tract. CRC Crit Rev Therapeutic Drug Carrier Systems 1990; 6: 273-313.

40. Daviskas E, Gonda I, Anderson SD. Mathematical modeling of heat and water transport in human respiratory tract. J Appl Physiol 1990; 69: 362-372.

41. Daviskas E, Gonda I. Mathematical models of heat and water vapor transport in the respiratory tract. Comments Theoret Biol 1992; 2: 335-355.

42. Boucher RC, Stutts MJ, Bromberg PA, Gatzy JT. Regional differences in airway surface liquid composition. J Appl Physiol: Respirat Environ Exercise Physiol 1981; 50: 613-620. 